\title{
THE IMPACT OF VISUAL SEQUENCING OF GRAPHIC SYMBOLS ON THE SENTENCE CONSTRUCTION OUTPUT OF CHILDREN WHO HAVE ACQUIRED LANGUAGE
}

\author{
Erna Alant*, Amelia du Plooy and Shakila Dada \\ Centre for Augmentative and Alternative Communication \\ University of Pretoria
}

\begin{abstract}
Although the sequence of graphic or pictorial symbols displayed on a communication board can have an impact on the language output of children, very little research has been conducted to describe this. Research in this area is particularly relevant for prioritising the importance of specific visual and graphic features in providing more effective and user-friendly access to communication boards. This study is concerned with understanding the impact of specific sequences of graphic symbol input on the graphic and spoken output of children who have acquired language. Forty participants were divided into two comparable groups. Each group was exposed to graphic symbol input with a certain word order sequence. The structure of input was either in typical English word order sequence Subject-Verb-Object (SVO) or in the word order sequence of Subject-Object-Verb (SOV). Both input groups had to answer six questions by using graphic output as well as speech. The findings indicated that there are significant differences in the PCS graphic output patterns of children who are exposed to graphic input in the SOV and SVO sequences. Furthermore, the output produced in the graphic mode differed considerably to the output produced in the spoken mode. Clinical implications of these findings are discussed.
\end{abstract}

Key Words: Augmentative and Alternative Communication, graphic symbol input, graphic symbol output, spoken output, sentence construction, word order.

\section{INTRODUCTION}

The field of Augmentative and Alternative Communication $(\mathrm{AAC})$ essentially deals with ways in which speech can be augmented or replaced by nonverbal strategies. A significant proportion of these strategies include the use of graphic symbols, for example, line drawings as a means to provide access to communication and learning for children and adults who might not have good reading or writing abilities.

The use of these graphic symbols on the children's receptive and expressive abilities has, however, not been well documented. Relatively few studies have been done to explore the impact of the use of graphic symbols on the language development of children.

One of the main issues in understanding the impact of the use of AAC strategies on the language development of children has to do with the acknowledgement of the asymmetrical relationship between the children's input, which is largely auditory with visual support (as with typical children) and their output which is much more focused on the AAC strategy as a means to augment existing communication. Smith and Grove (2003) discussed the asymmetry in input and output of individuals that use $\mathrm{AAC}$ and maintained that there are at least three factors that can influence the language acquisition process of an individual using AAC, these being the structural characteristics of the target language (spoken language), the nature of the input provided (auditory and/or visual), as well as the uptake, referring to the child's processing of the input received. The influence of the structural characteristics of the target language is related to the degree of congruence between the structure of the target language and the sequencing of the graphic symbols on the display. The demands that the AAC strategy

\begin{tabular}{|c|c|}
\hline Address: & $\begin{array}{l}\text { Centre for Augmentative and Alternative Communication } \\
\text { University of Pretoria }\end{array}$ \\
\hline & $\begin{array}{l}\text { Pretoria } \\
0002\end{array}$ \\
\hline Telephone: & $* * 27 \quad 124202001$ \\
\hline $\begin{array}{l}\text { Fax: } \\
\text { Email: }\end{array}$ & **27124204389 \\
\hline
\end{tabular}

imposes on the cognitive processing of the individual and how these demands impact on the uptake of the individual, is of additional concern. The relative importance of all of these factors is, however, unresolved (Harris, 1992; McDonald, 1997).

Regarding the development of syntactic skills in persons using AAC, research evidence points to atypical patterns of expression, such as a reliance on single-word utterances (Bruno, 1989; von Tetzchner \& Martinsen, 1996), relatively high frequency of word order errors (Grove, 1995; Grove \& Dockrell, 2000; van Balkom \& Donker-Gimbrère, 1996) and lack of internal morphological or clause structure (Grove, 1995). When considering possible influences leading to atypical syntax amongst AAC users, Oxley and von Tetzchner (1999) acknowledge that syntax and morphology of graphic systems are connected to the visual properties of the systems. Furthermore, construction of graphic 'sentences' might be compromised by the user's motor skills and coordination. Structure might be imposed by the forced choices users must make given the availability of graphic signs.

There has been increased interest over the past years in the organisation of the aided symbol displays and how to match these as closely as possible to internal cognitive or lexical strategies held by the AAC user (Light, et al., 2004). The assumption is that the user would find it easier to identify symbols if the display board more closely resembles the sequence of the language of input. Nakamura, Newell, Alm and Waller (1996) asked English-speaking adults to compose picture-based sentences using a computer-based system. Subject, Verb and Object Picture Communication Symbols (PCS) (MayerJohnson, 1985) could be selected by activating the corresponding button on the computer screen. This particular study utilized two conditions to analyze the impact of symbol ordering on picture-based sentence construction. In the SVO condition, the symbols were in the typical English word order sequence (Subject-Object Verb) and in the SOV condition, the symbols were in the atypical word order sequence (Subject-ObjectVerb). Twenty- one subjects were assigned to the SVO condition and 22 subjects were assigned to the unfamiliar SOV con- 
dition. The results showed that the English subjects used English word order in both conditions. In this study both groups were able to express themselves in the English word order regardless of the sequence of the graphic symbols on the display. In spite of the presentation of the symbols in an order not similar to that of their mother-tongue, adults were able to make the adjustment to present their answers in the correct symbol order.

It is against this background that the question arises as to the impact that the sequence in which symbols are presented could have on the output of children who have already acquired language. Furthermore, the graphic output mode needs to be compared to a spoken output mode. This study specifically investigated the impact of a subject-verb-object (SVO) sequence and a subject -object-verb (SOV) sequence of symbols on graphic displays for children with intact language acquisition. As a first step, this research was conducted on typically developing children to provide a basis for application to users with little or no functional speech. This information will thus enhance understanding of how typically developing children are able to manipulate graphic symbols in the process of language learning.

\section{METHODOLOGY}

\section{Aims}

The study aimed to answer the following questions:

- What is the syntactic structure of the graphic output constructed by children who have acquired language in response to a SVO graphic input condition (i.e. the selection display is organised in a SVO structure)?

- What is the syntactic structure of the graphic output constructed by children who have acquired language in response to a SOV graphic input condition?

- How does the syntactic structure of the graphic output compare for the two input conditions?

- How does the graphic output compare to spoken output?

\section{Design}

A control group design was used. The participants were randomly assigned to two groups. Half of the participants received the SVO input and the other half received SOV input. Even distribution of male and female participants in the two groups was ensured.

\section{Participants}

All the participants of this study were typically developing children who met the following selection criteria: the children and their parents consented to their participation in the study, they were between the ages of 7.5 to 8.5 years; spoke English as the primary language; had no reported language impairments; had reportedly normal vision and hearing; had prior experience with using computers and had the ability to use a mouse.

\section{Material}

\section{The graphic-based communication system}

The study was conducted using a computer-based program specially designed for the purpose. It consisted of a computer-generated story that was told to the participants using graphic symbols and then providing them with questions based on this story. These questions had to be answered by looking at graphic symbols presented in two different sequences, namely SVO and SOV sequences.

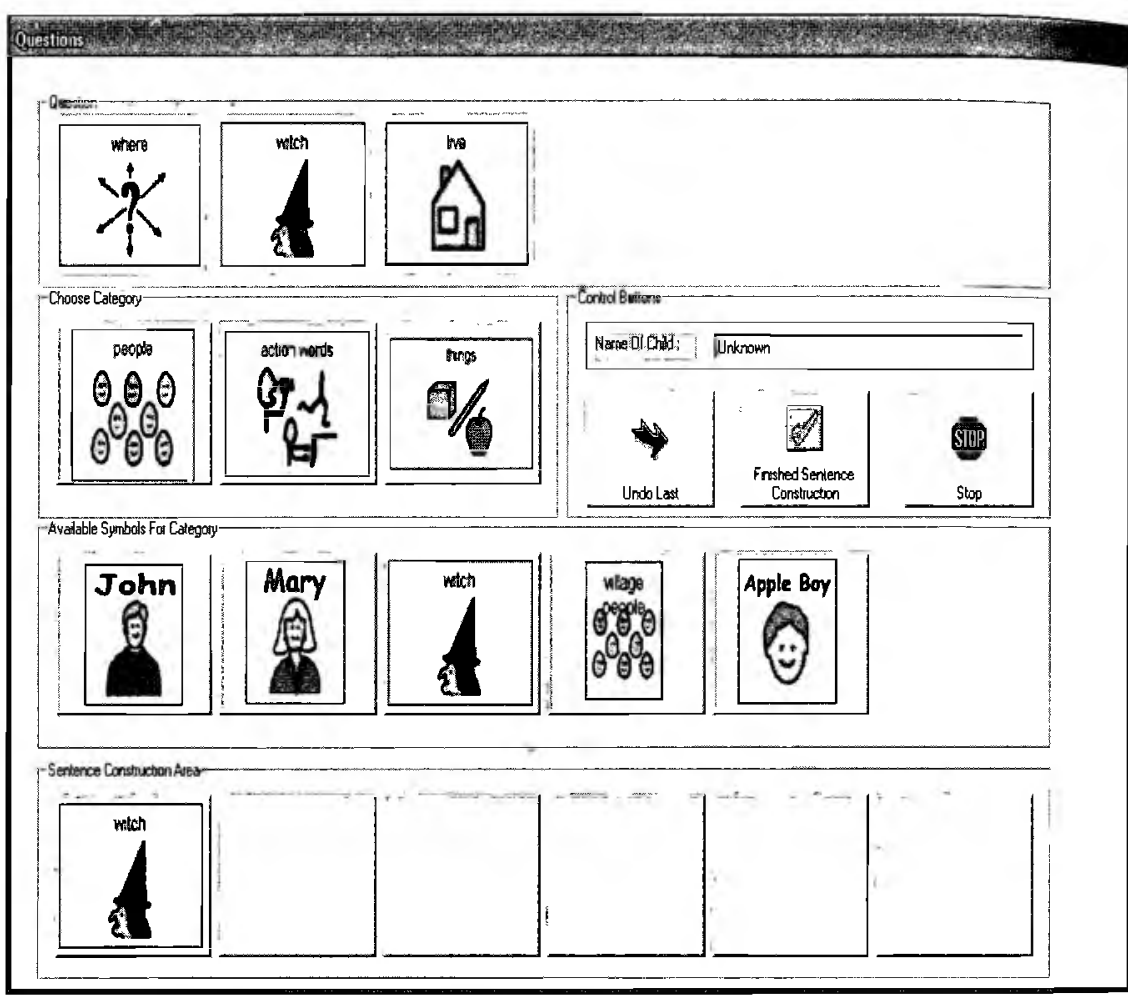

Figure 1: Answering questions using PCS: The SVO exposure

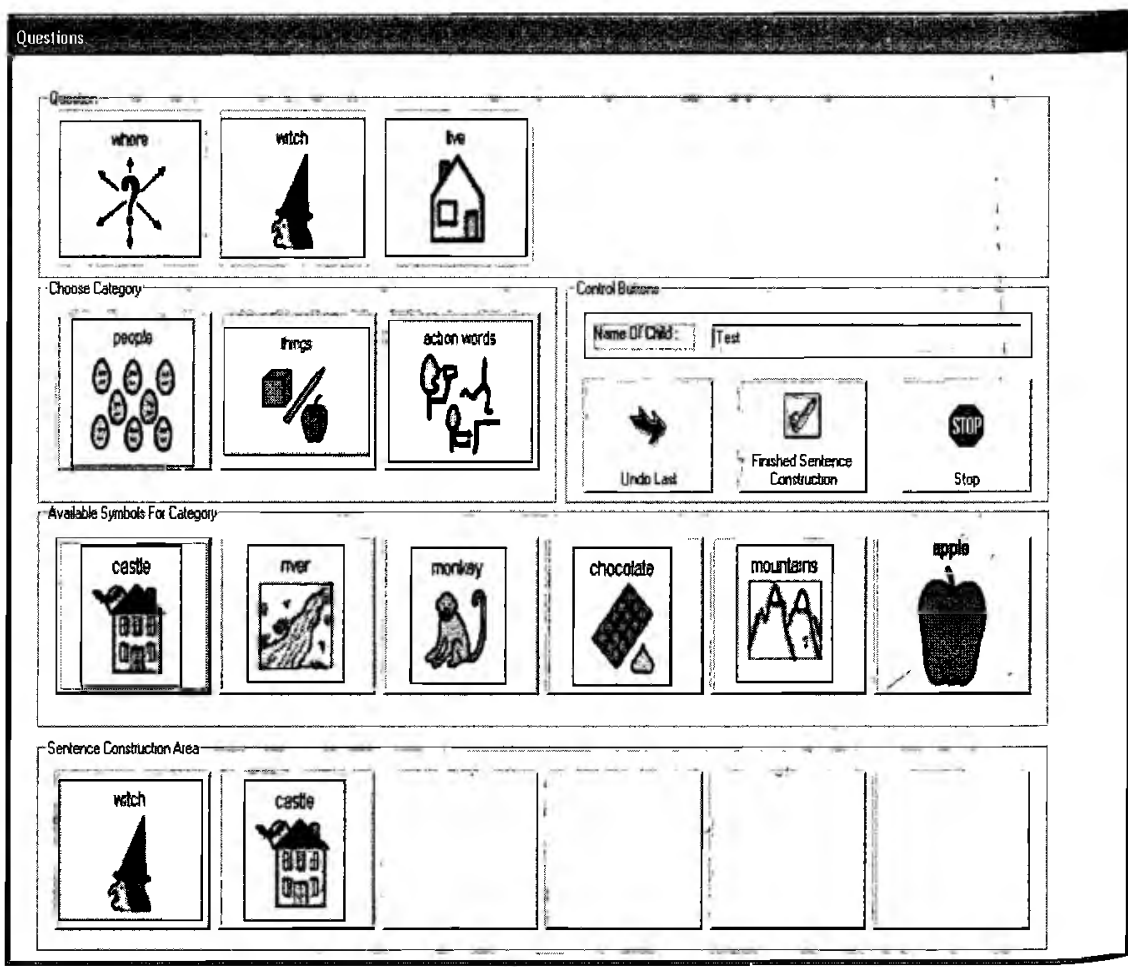

Figure 2: Answering questions using PCS: The SOV exposure 
The graphic-based communication system was developed on a personal computer (PC) using the picture communication symbols (PCS) construction package Boardmaker ${ }^{\mathrm{TM}}$ (MayerJohnson, 1985) and the software program Visual Basic. A mouse-driven interface was provided. In the 'Choose a category' section, three buttons were displayed on the screen corresponding to the three basic parts of speech: a subject button (people), a verb button (action), and an object button (things). Each of these buttons, when activated, provided a list of appropriate PCS symbols and participants could then choose one of the PCS symbols. For example, if a participant touched the subject button, five PCS symbols representing subjects (namely John, Mary, Witch, Apple Boy and village people) were displayed. When the participant chose a particular subject, the selected symbol was displayed on the screen and the computer spoke the corresponding word. In the SVO input the sequence of buttons in the "Choose a category" section was in the typical English word order sequence (Subject-Verb-Object) and in the SOV input the word order was Subject-Object-Verb.

A visual cue (moving face) was provided to assist the participants in finding their marker on the screen. A button was included to delete unwanted symbols. The learners indicated that they had completed a question by clicking on the "finished" button. The computer recorded the participant's responses, including deleted symbols. By including the deleted symbols, some insight into the underlying process of PCS sentence construction can be acquired. For more information on the communication system please consult Du Plooy (2004).

\section{The story}

Nakamura et al. (1996) developed a picture communication system and a set of questions based on the Japanese folk story "Momo-tarou" (The Apple Boy). Adaptations were made to the story to ensure age and cultural appropriateness for the participants. The teachers' suggestions and the pilot study results were used to make the necessary adaptations. See appen$\operatorname{dix} A$ for the adapted story as well as the questions used in the study. Seven illustrations were made using the Boardmaker ${ }^{\mathrm{TM}}$ program to use as visual stimuli to support the computer generated story.

\section{Procedure}

\section{Training}

The participants were trained in groups of 5 . The training included teaching the categorization process needed to select a PCS symbol, practising the combination of PCS symbols into sentences as well as listening to "The Apple Boy". The training procedure was audio-recorded.

During the categorization process the researcher explained the concept of graphic symbols and introduced the PCS symbols. The trainer then asked the participants to place the symbols in the categories of people, actions and things. Then they were trained on how to construct sentences using these graphic symbols by presenting them with sentences e.g. "Boy reads book" and asking them to represent these using graphic symbols. This training took place away from the computer. The final stage in the training process required that they had a first exposure to the "Apple boy story" away from the computer using stimulus pictures to ensure their familiarity with it once they were exposed to the computer generated version of the same story.

\section{Testing procedure}

The participants were tested individually. They listened to a recorded version of the "Apple Boy" on the computer. Illustra- tions were shown as the computer told the story. The participants were told that they had to listen to the story again, because they had to answer some questions about the story. The participants were introduced to the PCS symbols that they had to use in order to answer the questions. Each question was spoken by the computer in correct English syntax and key concepts were represented by the PCS symbols. The question "Where did the witch live?" for example, was accompanied by the symbols 'where', witch' and 'live'. Each participant answered six questions by choosing and selecting PCS symbols on the computer to form sentences. When the participant chose a particular symbol, it was displayed on the screen and the computer spoke the corresponding word. Figures 1 and 2 inserted before provide screenshots of Question 1: SVO input and Question 1: SOV input respectively. Participants had to click on the finished button to go on to the next question. Responses were automatically saved on the computer

The same questions were then asked verbally and each participant was required to give a spoken answer. Their responses were recorded. The spoken response mode always followed the picture-based answers.

\section{Reliability of data}

Procedures were recorded and $20 \%$ of the data was rated for procedural integrity by an independent rater. Results showed $97.5 \%$ integrity for the training procedure across all four groups and $100 \%$ integrity on the testing procedure.

\section{Analysis of data}

Two hundred and thirty two PCS responses were analysed, 112 for the SVO graphic input condition, and 120 for the SOV graphic input condition. Two hundred and twenty five spoken responses were analyzed.

Each symbol was classified as subject (S), verb (V) or object $(\mathrm{O})$. The responses were then classified into four types. The following responses are examples of responses classified as SVO: "live castle", "Witch live castle", "give chocolate monkey" and "Apple Boy give monkey chocolate". The second type, namely SOV responses, include responses like "castle live", "monkey chocolate give", and "Witch castle live" as well as "Apple Boy chocolate monkey". The third type was the single symbol utterances and the fourth type was used for sentences that could not be categorized into any of these types.

\section{RESULTS AND DISCUSSION}

A Chi-square test was done to test for a relationship between input and output sequence. However due to small frequencies in some of the cells, the test may not be valid and for the discussion of Table 1, emphasis will be placed on the difference between the expected and actual frequencies for this data

Table 1 indicates that the total frequency for outputs in the SVO input condition (112) was slightly lower than for the SOV input condition (120). A different pattern of responses between the two groups is also evident. For the SVO condition, the expected frequency for SVO outputs is 25 whilst the actual row frequency is 11 . This reflects less SVO outputs than expected. For using single symbols, the expected frequency is 58 whilst the row frequency is 73 . This suggests that participants produced less multiple symbol outputs in the SVO input condition than expected and more single utterances. The tendency to use more single utterances is not surprising as single 
Table 1: Analysis of different PCS output sequences

\begin{tabular}{|ccccccc|}
\hline \multirow{3}{*}{ SVO input } & SVO & $\begin{array}{c}\text { SINGLE } \\
\text { SYMBOLS }\end{array}$ & SOV & OThER & TOTAL \\
\hline & $\begin{array}{c}\text { Observed } \\
\text { frequency }\end{array}$ & 11 & 73 & 5 & 23 & 112 \\
$\begin{array}{c}\text { Expected } \\
\text { frequency } \\
\text { Row percentage }\end{array}$ & 25 & 58 & 4 & 25 & \\
\cline { 2 - 7 } SOV input & $\begin{array}{c}\text { Observed } \\
\text { frequency }\end{array}$ & 41 & 47 & 3 & 29 & 120 \\
& $\begin{array}{c}\text { Expected } \\
\text { frequency }\end{array}$ & 27 & 62 & 4 & 27 & \\
\hline \multirow{2}{*}{ Row percentage } & 34 & 39 & 3 & 24 & \\
\hline \multirow{2}{*}{ ROTAL } & Frequency & 52 & 120 & 8 & 52 & 232 \\
& Percentage & 22 & 51 & 3 & 22 & 100.00 \\
\hline
\end{tabular}

Chi-Square: DF 3; Value 23.88; $<<0001$

Note: $25 \%$ of the cells have expected counts less than 5 .

utterances are often used as responses to questions (Von Tetzchner \& Martinsen, 1996).

For the SOV input condition the output frequency for SVO is 41 which is higher than the expected frequency of 27 , whilst outputs in terms of single symbol utterances are lower (47 than expected 62). This implies that the children, even on a graphic level, were able to correct for the SOV presentation of symbols to respond with the traditional SVO sequence. The fact that few SOV responses were given confirm this finding.

When comparing the row percentages between the different input conditions for graphic output responses in Table 1, the most striking of the differences include the higher percentage of SVO responses $(34 \%)$ in the SOV input condition and the lower percentages $(39 \%)$ of single symbols in the SOV input condition. Both these findings could reflect a more conscious effort from the children in the unfamiliar SOV input sequence condition in fulfilling the requirements of the task, resulting in more grammatically complete responses. On the other hand, the SVO input condition elicited more automatic responses from the children reflecting more single utterance responses and less full sentences. Thus, despite their intact expressive and receptive language, these children used an overall high percentage of single symbol utterances (65\% and $39 \%$ ). These findings are supported by Smith (1996) who found similar patterns of picture reduction in typical children when using graphic output.

Table 2: Analysis of the percentages of different spoken output sequences

\begin{tabular}{|c|c|c|c|c|}
\hline & & svo & $\begin{array}{l}\text { SINGLE UT: } \\
\text { TERANCE }\end{array}$ & TOTAL \\
\hline \multirow{3}{*}{ svo input } & $\begin{array}{l}\text { Observed } \\
\text { frequency }\end{array}$ & 33 & 74 & \multirow[t]{3}{*}{107} \\
\hline & $\begin{array}{l}\text { Expected } \\
\text { frequency }\end{array}$ & 35 & 72 & \\
\hline & Row percentage & 31 & 69 & \\
\hline \multirow{3}{*}{ soV input } & $\begin{array}{l}\text { Observed } \\
\text { frequency }\end{array}$ & 41 & 77 & \multirow[t]{3}{*}{118} \\
\hline & $\begin{array}{l}\text { Expected } \\
\text { frequency }\end{array}$ & 39 & 79 & \\
\hline & Row percentage & 35 & 65 & \\
\hline \multirow{2}{*}{ TOTAL } & Frequency & 74 & 151 & 225 \\
\hline & Row Percentage & 66 & 134 & 100 \\
\hline
\end{tabular}

Chi-Square: DF 1; Value $0,3876, \mathrm{p}=0,5336$ not significant
Overall, a total of $25 \%$ and $27 \%$ (for SVO and SOV input conditions respectively) of graphic output utterances of the participants deviated from the accepted English word order. These percentages are obtained by adding the percentages of utterances classified as SOV and those classified as 'other' This relatively high percentage might suggest that the students found the task quite difficult in both input conditions.

Table 2 represents the spoken outputs of the children in the two groups (SVO input condition and SOV input condition). Overall number of utterances indicated that the SOV input condition produced slightly less spoken utterances (107 as opposed to 118). When compared in terms of the different categories of spoken output, it is evident that there are no significant differences between the speech outputs of the two groups in response to the questions. No responses categorized as "other" or SOV speech output were noted. All participants had acquired language, and it is thus not surprising that there is no statistical difference between these two groups on the type of verbal outputs.

When comparing each of the input modes, it becomes evident that in both the SVO and SOV input modes, the graphic outputs were more varied, whilst the speech output of both groups was very similar. The above findings are both interesting and thought-provoking in terms of clinical implications for intervention. It is indicated that for graphic outputs, the SOV input condition had a significant impact on the expression of the participants.

These findings evoke interesting questions in relation to principles of symbol organization on communication boards. If the child is using graphic input and output, where one symbol represents one concept, attention to the sequence of the graphic symbols on the communication board is likely to impact on expression, even if the child has acquired syntactic abilities. In contrast, a child using verbal language output will use his/her internalized syntactical knowledge to organise output.

This impact of the sequence of graphic symbol input might be reduced if other visual features that could impact on symbol selection e.g. color coding, were employed. The Aided Language Stimulation approach by Goossens', Crain and Elder (1992) for example, colour codes the different parts of speech (nouns, verbs etc.), which might aid correct output sequencing, provided the user has the metalinguistic knowledge to use such colour coding to his or her advantage.

Also, when using graphic systems that do not have a one-on-one relationship concept-to-symbol (such as those employing semantic encoding), sequencing of symbolsi on the display might not influence the syntax of output in the same way. Semantic encoding employs combinations of a finite set of graphic symbols to generate an infinite number of concepts. Arguably the syntax of output would be more directly related to the child's inherent linguistic and specifically syntactic abilities.

These findings can also be interpreted in relation to linguistic processing in a visual versus an auditory mode. When children had to provide graphic output based on graphic input, the syntax of their output deviated from the accepted English word order, in spite of the fact that they had, intact syntactic abilities, as evidenced by their correct verbal output. This might reflect that these children were less experienced to translate their answers into a visual mode, while they were well able to formulate syntactically correct answers in a spoken (auditory) mode. One could argue that as these children are relatively young and not well established in reading and writing skills, they might be less able to construct correct sentences on a visual processing level. This alludes to a difference be- 
tween the auditory and visual processing skills of the children at this stage of their development. The task of recoding a message from speech to a graphic or visual modality is complex for AAC users (Smith \& Grove, 2003) and based on the results of this study even for individuals with intact language abilities. The cognitive processing demands for AAC users that have speech as input and graphic symbols as an output have been better understood from a dual coding theory perspective (Paivio, 1971; 1986). Dual coding theory outlines two separate cognitive subsystems that process stimuli, depending on whether the stimulus is verbal or nonverbal. The idea of separate subsystems implies that they are structurally and functionally distinct. The two systems are independent in terms of information processing. However, activity in one subsystem is said to trigger activity in the other. This implies an underlying assumption that there are interconnections between the two systems. From an AAC perspective, the argument has been that these interconnections serve to facilitate language development in AAC users as the two modalities complement and not compete with each other. However, one could argue that interconnections between the systems is less developed in the participants in this study as they had already acquired language, and had no experience with an $\mathrm{AAC}$ system as output mode.

\section{CRITICAL EVALUATION OF THE STUDY AND FUTURE RESEARCH}

This study has several limitations which are important in view of the interpretation of the data. In the first instance, the study was done on typically developing children who have acquired language. Since little is known about the impact of graphic input on language output, the use of typical children allows the examination of this association before extending knowledge to children with physical or intellectual disabilities in the performance of the same tasks. Generalization to other populations, for example, children with little or no speech should thus be done with great caution.

Secondly, the potential effect of the ungrammatical sequence of the graphic input could have been more prominent if the questions asked included more open questions. Future research must incorporate more open questions to confirm whether the ungrammatical input has an inhibiting effect on responses requiring more free expression.

Thirdly, the tasks used provided limited symbols on a screen, which is not necessarily representative of a communication overlay as generally used by AAC users. Further research could investigate the impact of communication boards sequenced differently on the output of children and adults of different ages. In addition, the impact of visual factors, for example, colour coding and its role in minimizing the impact of unfamiliar visual sequencing e.g. SOV on ease of use in children and adults, could shed light on the basic importance of symbol sequence as one feature to consider in the development of communication displays.

\section{ACKNOWLEDGEMENTS}

This study was originally based on a masters study in AAC by Amelia du Plooy under the guidance of Prof Erna Alant and Dr Shakila Dada at the CAAC, University of Pretoria. Rina Owen from the Department of Statistics at the University of Pretoria assisted with the data analysis of the study.

\section{REFERENCES}

Bruno, J. (1989).Customizing a Minspeak system for a preliterate child: A case ex. ample. Augmentative and Alternative Communication, 5, 89-100.

Du Plooy, A. (2004). The impact of visual sequencing of pictures on the picturebased sentence construction of English-speaking Grade 2 learners. Master's Thesis, Centre for AAC, University of Pretoria, South Africa.

Goossens, C., Crain, S., \& Elder, P. (1992). Communication displays for engineered preschool environments: Books 1 and 2. Solana Beach, CA: Mayer-JohnsonCo.

Grove, N. (1995). An analysis of the linguistic skills of signers with learning disabilities. Unpublished doctoral dissertation, University College, London.

Grove, M. \& Dockrell, J. (2000). Multi-sign combinations by children with intellectual impairments: An analysis of language skills. Journal of Speech, Language, and Hearing Research, 43, 309-323.

Harris, M. (1992). Language experience and early language development. Hove: Lawrence Erlbaum Associates.

Hemmeter, M. L., \& Kaiser, A. P. (1994). Enhanced milieu teaching: Effects of parent-implemented language intervention. Journal of Early Intervention, 17(1), $85-99$.

Light, J., Drager, K., McCarthy, J. Mellot. S., Millar, D., Parrish, C., et.al. (2004) Performance of typically developing four-and five-year-old children with AAC systems using different language organization techniques. Augmentative and Alternative Communication, 20(2). 63-88.

Mayer-Johnson, R. (1985). The Picture Communication Symbols. Solana Beach: MayerJohnson.

McDonald, J. (1997). Language acquisition: The acquisition of linguistic structure in normal and special populations. Annual Review of Psychology, 48, 215-241.

Nakamura, K., Newell, A., F. Alm, N., \& Waller, A. (1996). How do members of different language communities compose sentences with a picture-based communication system? - A cross-cultural study of picture-based sentences constructed by English and Japanese speakers. Augmentative and Alternative Communication, 14, 71-79.

Oxley, J., \& von Tetzchner, S. (1999). Reflections on the development of alternative language forms. In F.Loncke, J. Clibben, H. Arvidson, \& L. Lloyd (Eds.), Augmentative and alternative communication: New directions in research and practice (pp. 62-74). London: Whurr.

Paivio, A. (1971). Imagery and verbal responses. Toronto: Rinnehart and Winston.

Paivio, A. (1986). Mental representations: $A$ dual coding approach. New York: Oxford University Press.

Smith, M. M. (1996), The medium or the message: A study of speaking children using communication boards. In S. Von Tetzchner, \& M. G. Jensen (Eds.) Augmentative and alternative communication: European perspectives (pp.137-152). London: Whurr Publishers.

Smith, M., \& Grove, N. (2003) Asymmetry in input and output. In J. Light, D. Beukelman, \& J. Reichel (Eds.) Communicative Competence for Individuals who Use $A A C$ (pg. 163-198). London: Paul H Brookes.

Van Balkom, H. \& Donker-Gimbrère, M. (1996). A psycholinguistic approach to graphic language use. In S. von Tetzchner, \& M. Jensen (Eds.), Augmentative and alternative communication: European perspectives (pp. 153-170). London: Whurr.

Von Tetzchner, S. \& Martinsen, H. (1996). Words and strategies: Conversations with young children who use aided language. In S. Von Tetzchner, \& M. G. Jensen (Eds.) Augmentative and alternative communication: European perspectives (pp. 65-88) London: Whurr publishers. 


\section{APPENDIX}

\section{Story}

John and Mary were living in a village. Sometimes, a witch who lived in the castle came to the village to steal the people's money. One day, John went to the mountain and Mary went to the river. When Mary was washing their clothes in the river, a big apple floated towards Mary. Mary picked it up and took it home. A baby was born from the apple. John and Mary named the baby Apple Boy. They loved him very much and took good care of him. When the Apple Boy grew up, he decided to fight the witch. On the way to the castle, the Apple Boy met a monkey and gave a chocolate to it. The monkey was so pleased that it promised to help the Apple Boy fight the witch. With the help of the monkey, the Apple Boy beat the witch. The witch was then forced to apologize to the village people.

\section{Questions}

1. Where did the witch live?

2. Where did John go?

3. Where did Mary go?

4. What did the Apple Boy give and to whom?

5. The Apple Boy and the witch had a big fight. What happened?

6. What did the witch finally do? 